\title{
Vascular Cell-Like Potential of Undifferentiated Ligament Fibroblasts to Construct Vascular Cell-Specific Marker-Positive Blood Vessel Structures in a PI3K Activation-Dependent Manner
}

\author{
Naoto Okubo ${ }^{a, b} \quad$ Akira Ishisaki $^{a}$ Tadashi lizukac Masato Tamura $^{a}$ \\ Yoshimasa Kitagawa ${ }^{b}$ \\ ${ }^{a}$ Department of Oral Biochemistry and Molecular Biology, Division of Oral Health Science, ${ }^{b}$ Department of Oral \\ Diagnosis and Oral Medicine, Division of Oral Pathobiological Science, and 'Support Section for Education and \\ Research, Graduate School of Dental Medicine, Hokkaido University, Sapporo, Japan
}

\section{Key Words}

Three-dimensional vessel reconstruction - Angiogenesis •

Tie-2 - FLK-1 • Differentiation - Fibroblasts • Endothelial

cell $\cdot$ Fibroblast growth factor $\cdot \mathrm{PI} 3 \mathrm{~K} \cdot$ Periodontal ligament

\begin{abstract}
Objective: To evaluate whether fibroblasts derived from periodontal ligament retain the ability to differentiate into putative vascular cells and construct vascular cell-specific marker-positive blood vessel structures. We also evaluated the morphological features of the structure and investigated the intracellular molecular mechanism underlying the angiogenic activity of these cells. Methods: Single cell-derived cultures (SCDCs) were established from primary rat ligament fibroblast cultures, and their expression of ligament cell-, mesenchymal stem cell- and vascular cell-specific markers was evaluated by RT-PCR and immunocytochemistry. The ability of the cells to construct a blood vessel structure was evaluated in a three-dimensional type I collagen scaffold. The morphological and immunohistological characteristics of the structure were then evaluated. Results: Each SCDC expressed endothelial cell (EC)-specific and smooth muscle cell-specific markers, in addition to mesenchymal stem celland ligament cell-specific markers. SCDC2 cells, which abun-
\end{abstract}

\section{KARGER}

Fax +41613061234 E-Mail karger@karger.ch www.karger.com (c) 2010 S. Karger AG, Basel

$1018-1172 / 10 / 0475-0369 \$ 26.00 / 0$

Accessible online at:

www.karger.com/jvr dantly expressed the EC markers Flk-1 and Tie-2, vigorously constructed a blood vessel structure in a phosphoinositide 3-kinase activation-dependent manner. Conclusion: Periodontal ligament fibroblasts have the potential to construct an EC marker-positive blood vessel-like structure. Consequently, the fibroblastic lineage in ligament tissue could be a candidate precursor for construction of a vascular system around damaged ligament tissue to facilitate its regeneration.

Copyright $\odot 2010$ S. Karger AG, Basel

\section{Introduction}

The periodontal ligament (PDL) is a fibrous connective tissue located between the tooth root and alveolar bone. PDL contains a heterogeneous mixture of cell types, including PDL fibroblasts, cementoblasts, osteoblasts, epithelial cells (rests of Malassez), vascular endothelial cells (ECs), smooth muscle cells (SMCs) and certain types of nerve cells [1]. In response to oral pathological and physiological environmental alterations such as periodontitis, wounding and tooth movement by orthodontic treatment, PDL cells have the capacity to reconstruct the periodontal structure. For tissue reconstruction, multi- 
potent progenitor cells or putative stem cells must be present in the PDL. The paravascular zones in the adult PDL contain the progenitors of fibroblastic and mineralised tissue-forming cell lineages, that is, the osteoblastic and cementoblastic lineages [2]. Recently, several studies have indicated that PDL fibroblastic cells share biological characteristics with bone marrow mesenchymal cells, suggesting that the mineralised tissue lineages may have originated from a common early progenitor cell [36]. Seo et al. [7] also demonstrated that PDL cells show cementoblastic/osteoblastic and adipogenic differentiation in vitro and have the potential to generate cementum/PDL-like tissue in vivo, suggesting that multipotent stem cells are present in PDL.

We previously demonstrated the ability of a swine PDL fibroblast cell line, TesPDL3, to express EC-specific markers in two-dimensional tissue culture plates and to construct a tube-like structure in a three-dimensional self-assembling peptide scaffold (PuraMatrix) [8]. Thus, PDL fibroblasts seem to show EC-like characteristics in specific cell culture systems. However, the self-assembling peptide does not contain the putative integrinbinding motif RGD (Arg-Gly-Asp) $[9,10]$ found in the abundant extracellular matrix protein fibronectin; the peptide scaffold does not activate RGD-dependent integrin-mediated intracellular signalling. In addition, the peptide scaffold does not contain the putative peptide sequence that binds fibronectin, which facilitates activation of integrin-mediated signalling in cells adhering to the peptide network. The RGD motif plays an important role in EC migration related to angiogenesis and neovascularisation through integrin-mediated intracellular signalling [11-13]. A mature continuous lumen throughout the tube-like structure constructed by TesPDL3 cells was not observed in sequential frozen sections of a cell culture in a peptide scaffold under bright-field microscopy (data not shown). Therefore, the ability of PDL fibroblasts to construct a vessel-like structure in the self-assembling peptide scaffold does not seem to be optimised. To discover whether PDL fibroblasts can differentiate into putative ECs that construct blood vessels with a mature lumen, we evaluated the ability of cells to vascularise in a three-dimensional type I collagen scaffold. The type I collagen scaffold contains many fibronectin-binding sites [14], and these promote EC vessel formation by presenting the RGD motif on fibronectin, which is secreted by fibroblasts and binds to the fibronectin-binding site, to ECs adhering to the type I collagen network.

The PDL cell line, TesPDL, was established by overexpression of human telomerase reverse transcriptase
(hTERT) in cells derived from swine PDL [15]. However, we cannot exclude the possibility that hTERT itself affects the expression of mesenchymal stem cell-like activity in cells derived from PDL. Li et al. [16] reported that hTERT-immortalised non-malignant human prostate epithelial cells retain the properties of multipotent stem cells. Thus, in order to define the multipotency of cells derived from PDL, it is necessary to eliminate the effects of exogenously introduced genes used to immortalise the cells, such as hTERT.

Here we first established several single cell-derived cultures (SCDCs) from a primary culture of rat fibroblasts derived from PDL by continuous stimulation of the cells with fibroblast growth factor (FGF)-1 plus heparin, without transfer of exogenous genes into the cells for the purpose of immortalisation. We then examined the expression of mesenchymal stem cell (MSC)-, ligament celland vascular cell-specific markers in each SCDC. We analysed the relationship between the ability of the cells to construct blood vessel structures and the expression of various cell-specific markers in PDL fibroblasts. In addition, we evaluated the morphological and histological characteristics of the blood vessel structures constructed by PDL fibroblasts. To identify intracellular signalling pathways that play an important role in the angiogenic activity of PDL fibroblasts, we assessed whether phosphoinositide 3-kinase (PI3K)/Akt- and MEK/extracellular signal-regulated protein kinase (ERK)-dependent intracellular signalling, which seem to play important roles in angiogenesis [17-19], affected the ability of the cells to construct the vessel-like structure.

\section{Materials and Methods}

Isolation of Rat PDL Fibroblasts and Cell Culture

Four Wistar strain male rats (4 weeks old, about 100 g) were sacrificed, and all of the molars were then extracted. To avoid gingival tissue contamination, supracrestal soft tissues attached to the cervical area of the molars were carefully curretted before extraction. Extracted molars with PDL were rinsed once in F-12 HAM (Sigma, St. Louis, Mo., USA) medium supplemented with kanamycin $(100 \mu \mathrm{g} / \mathrm{ml})$. The molars were then immersed in digestion solution, $20 \mathrm{ml}$ of F-12 HAM containing $2 \mathrm{mg} / \mathrm{ml}$ of collagenase consisting of class I and class II collagenases (Collagenase NB4; Wako, Tokyo, Japan), at $37^{\circ} \mathrm{C}$ for $20 \mathrm{~min}$ with continuous vigorous rocking. The solution was centrifuged to collect the tissue released from the surface of the roots of teeth. The released tissue was then treated with $0.1 \%$ trypsin (Difco Laboratories, Detroit, Mich., USA) in phosphate-buffered saline (PBS) at $37^{\circ} \mathrm{C}$ for 10 min with continuous vigorous rocking. The solution was then centrifuged to collect the cells released from the tissue. The cells were then cultured on type I collagen-coated plastic plates (Sumi- 
lon Celltight Plate; Sumitomo Bakelite Co., Tokyo, Japan) in F-12 HAM supplemented with $10 \%$ foetal bovine serum (FBS; PAA Laboratories GmbH, Pasching, Austria), $10 \mathrm{ng} / \mathrm{ml}$ of FGF-1 (R\&D Systems Inc., Minneapolis, Minn., USA), $15 \mu \mathrm{g} / \mathrm{ml}$ of heparin (Sigma), and $100 \mu \mathrm{g} / \mathrm{ml}$ of kanamycin (Sigma) in a humidified atmosphere of $5 \% \mathrm{CO}_{2}$ at $37^{\circ} \mathrm{C}$. Heparin was included to achieve optimal FGF-1 activity [20]. The culture medium was changed once every 3 days, and cells obtained from the third to seventh passages were used in the following studies. This study was carried out in accordance with the guidelines on the care and use of laboratory animals issued by Hokkaido University.

\section{Establishment of SCDC from a Rat PDL Primary Fibroblast} Culture

The cultured primary rat PDL fibroblasts described above were seeded into each well of a type I collagen-coated 96-well plastic plate (Sumilon Celltight multi-well plate; Sumitomo Bakelite Co.) at a density of 1 cell/well. The cells were maintained in F-12 HAM supplemented with $20 \%$ FBS, $10 \mathrm{ng} / \mathrm{ml}$ of FGF-1, $15 \mu \mathrm{g} / \mathrm{ml}$ of heparin and $100 \mu \mathrm{g} / \mathrm{ml}$ of kanamycin in a $5 \% \mathrm{CO}_{2}$ humidified atmosphere at $37^{\circ} \mathrm{C}$. The culture medium was changed once every 2 days. Individual cells from each well of the 96-well plate were deposited into the SCDC. Each SCDC was expanded to a sub-confluent culture on a type I collagen-coated plastic plate (Sumilon Celltight Plate; Sumitomo Bakelite Co.) with a diameter of $9 \mathrm{~cm}$. Cells obtained from the third to seventh passages were used in the following studies.

\section{RT-PCR Analysis}

Total RNA was extracted from the primary culture of rat PDL fibroblasts and SCDCs using Isogen (Nippongene Co., Toyama, Japan), according to the manufacturer's protocol. Complementary DNA (cDNA) was synthesised with Omniscript reverse transcriptase (Qiagen, Valencia, Calif., USA) using $(\mathrm{dT})_{15}$ primer (1 $\mathrm{mM})$. Subsequent amplification for detection of cDNAs was performed for each cell using the requisite number of cycles under the following conditions: $94^{\circ} \mathrm{C}$ for $30 \mathrm{~s}$, the annealing temperature optimised for each primer pair for $30 \mathrm{~s}$ and $72^{\circ} \mathrm{C}$ for $90 \mathrm{~s}$. The primer sequences used for PCR amplification (table 1) were designed using rat mRNA cDNA sequences for MSC markers [CD44, CD146, vascular cell adhesion molecule 1 (VCAM1), smooth muscle $\alpha$-actin (SM $\alpha$-actin), alkaline phosphatase (ALP)], ligament fibroblast markers [scleraxis, periostin, $\alpha 1$ (I)procollagen, osteopontin (OPN)], osteoblast markers [osterix, osteocalcin (OCN), runt-related transcription factor 2 (Runx2)], SMC markers (h1-calponin, smoothelin), EC markers [Tie-2, Flk-1, von Willebrand factor (vWF), CD31] and $\beta$-actin. Amplified products were separated by agarose gel electrophoresis and stained with ethidium bromide. PCR experiments were performed using samples from at least 3 different cell preparations, and the results were confirmed by triplicate PCR experiments using the same cell samples.

Construction of a Blood Vessel-Like Structure by SCDC Cells in the Three-Dimensional Type I Collagen Scaffold

In order to evaluate the ability of SCDC cells to construct a blood vessel-like structure, we modified an angiogenesis assay used for spheroid-based engineering of the vasculature [21]. First, cells were suspended in $100 \mu \mathrm{l}$ of F-12 HAM supplemented with $20 \%$ FBS and FGF plus heparin and seeded into a well of a 96 -well plastic plate (Sumilon Celltight Spheroid multi-well plate; Sumitomo Bakelite Co.) at a density of $1.0 \times 10^{4}$ cells/well. The cells were then incubated in a $5 \% \mathrm{CO}_{2}$ humidified atmosphere at $37^{\circ} \mathrm{C}$ for $48 \mathrm{~h}$. During the incubation, the cells migrated toward one another and formed a cell cluster, resembling a spheroidal aggregation of cells. This cell cluster was transferred into the type I collagen gel scaffold, which was prepared as follows: the gel was fabricated by mixing 2 volumes of $0.3 \%$ type I collagen solution (Cellmatrix I-A; Nitta Gelatin, Osaka, Japan), 4 volumes of sterilised water, 2 volumes of FBS, 1 volume of $10 \times$ concentrated F-12 $\mathrm{HAM}$ and 1 volume of reconstitution buffer $\left(260 \mathrm{~mm} \mathrm{NaHCO}_{3}\right.$, $200 \mathrm{mM}$ 4-(2-hydroxyethyl)-1-piperazineethanesulfonic acid and $50 \mathrm{~mm} \mathrm{NaOH}$ in sterilised water). Then, $100 \mu \mathrm{l}$ of the mixture was pipetted onto the bottom of a well in a 96-well tissue culture plate and incubated at $37^{\circ} \mathrm{C}$ for $30 \mathrm{~min}$ to solidify the mixture. After solidification, the spheroidal aggregate of cells constructed as described above was placed onto the centre of the solidified gel, and an additional $100 \mu \mathrm{l}$ of the type I collagen gel mixture was then placed over the cells and allowed to solidify. Finally, $100 \mu \mathrm{l}$ of F12 HAM supplemented with $20 \%$ FBS and FGF plus heparin was added to the culture and incubated for the indicated time. Where indicated, the MEK inhibitor U0126 or PI3K inhibitor LY294002 (all from Calbiochem) was added to the type I collagen gel and culture medium. The vessel-like structures originating from the surface of the spheroidal aggregate were viewed under a phasecontrast microscope and photographed. The spheroid test was also performed for the uniformly solidified type I collagen gel. We confirmed that the vessel-like structures originating from the surface of the spheroidal aggregate sprouted from the uniformly solidified gel, as observed in the gel solidified using 2 steps (methods described above) (data not shown).

\section{Paraffin Sections of the Three-Dimensional Cell Culture in the} Type I Collagen Gel

First, the three-dimensional cell culture in the type I collagen gel was fixed with $10 \%$ formalin for more than 3 days, and then stored in $70 \%$ ethanol overnight for dehydration. The specimen was then sequentially dehydrated in 70, 80, 90, 95 and 100\% ethanol. After dehydration, the specimens were exposed to lemosole (Wako), and then embedded in $100 \%$ paraffin at $64-68^{\circ} \mathrm{C}$ (Wako). The paraffin-block was sectioned at $5 \mu \mathrm{m}$ using a microtome REM-700 (Yamato, Saitama, Japan) and disposable metal blades (Feather, Tokyo, Japan). Sections were collected on MAS-coated glass slides and incubated at $37^{\circ} \mathrm{C}$ overnight for immobilisation. They were then deparaffinised in lemosole for $20 \mathrm{~min}$, hydrated in a graded ethanol series (1-3 min each), and stained with haematoxylin-eosin for $1 \mathrm{~min}$ (Mutokagaku, Tokyo, Japan) or used for immunohistochemical analysis. In some cases, cells in the type I collagen gel were first fluorescently labelled using the PKH67 Green Fluorescent Cell Linker Kit (Sigma), according to the manufacturer's instructions. Fluorescence was detected using a BZ-9000 all-in-one fluorescence microscope (Keyence, Osaka, Japan).

\section{Celloidin Sections of the Three-Dimensional Cell Culture in the Type I Collagen Gel}

The cells were first fluorescently labelled as described above. Then, three-dimensional cultures of the labelled cells in the type I collagen gel were fixed with $10 \%$ formalin for more than 3 days. After several washes in distilled water and dehydration in the 
Table 1. Primers used for RT-PCR

\begin{tabular}{|c|c|c|c|c|}
\hline Specificity & Ologonucleotide sequence $\left(5^{\prime}-3^{\prime}\right)$ & $\begin{array}{l}\text { Annealing } \\
\text { temp., }{ }^{\circ} \mathrm{C}\end{array}$ & $\begin{array}{l}\text { Predicted } \\
\text { size, bp }\end{array}$ & Cycle \\
\hline CD44 & $\begin{array}{l}\text { TACCTGGGAAGACCTAGGAGCA } \\
\text { TTCGCAAGCCAGTTGGTACTTA }\end{array}$ & 58 & 213 & 36 \\
\hline CD146 & $\begin{array}{l}\text { ACCACCCTCACACCTGACTC } \\
\text { TCTCCTGTTTTCCTGAGCGT }\end{array}$ & 58 & 235 & 38 \\
\hline VCAM1 & $\begin{array}{l}\text { CTCCAGATGTAGGTCAGAAC } \\
\text { TAATCAGTATACCATGAATTAGG }\end{array}$ & 51 & 291 & 38 \\
\hline $\mathrm{SM} \alpha$-actin & $\begin{array}{l}\text { CGATAGAACACGGCATCATC } \\
\text { CATCAGGCAGTTCGTAGCTC }\end{array}$ & 59 & 524 & 30 \\
\hline ALP & $\begin{array}{l}\text { CGCCTATCAGCTAATGCACA } \\
\text { AGGGAAGGGTCAGTCAGGTT }\end{array}$ & 59 & 315 & 35 \\
\hline Scleraxis & $\begin{array}{l}\text { CGAGAACACCCAGCCCAAACAGAT } \\
\text { ATAGCCCGCCTGTCCATCTC }\end{array}$ & 62 & 281 & 35 \\
\hline Periostin & $\begin{array}{l}\text { TGTGGGGTAGGAACTGAAGG } \\
\text { TCCAGCCTCTTCTTGACCAT }\end{array}$ & 59 & 157 & 38 \\
\hline$\alpha 1(\mathrm{I})$ procollagen & $\begin{array}{l}\text { GGAGAGAGTGCCAACTCCAG } \\
\text { CCACCCCAGGGATAAAAACT }\end{array}$ & 59 & 206 & 30 \\
\hline OPN (osteopontin) & $\begin{array}{l}\text { GAAACTCCTGGACTTTGACC } \\
\text { GCCACTTGGCTGAAGCCTG }\end{array}$ & 55 & 357 & 30 \\
\hline Tie-2 & $\begin{array}{l}\text { GGGCAAAAATGAAGACCAGCAC } \\
\text { GCATCCATCCGTAACCCATCCT }\end{array}$ & 61 & 512 & 38 \\
\hline Flk-1 & $\begin{array}{l}\text { GGGAAAGACTATGTTGGG } \\
\text { ATCAATCTTGACCCCAGG }\end{array}$ & 52 & 498 & 38 \\
\hline vWF & $\begin{array}{l}\text { GCCTCTACCAGTGAGGTTTTGAAG } \\
\text { АTCTCATCTCTTCTCTGCTCCAGC }\end{array}$ & 61 & 297 & 38 \\
\hline CD31 & $\begin{array}{l}\text { AGGTGACCGTGGACAAAAAG } \\
\text { TCCGGATGAATTCTGAGGTC }\end{array}$ & 58 & 266 & 38 \\
\hline Ang-1 & $\begin{array}{l}\text { GTTTTTGTGCTGGGTCTGGT } \\
\text { GTGGTGATCTGGAAGGGAGA }\end{array}$ & 60 & 278 & 35 \\
\hline Smoothelin & $\begin{array}{l}\text { CCTACAGGCAACCAGAGAGC } \\
\text { TTCCGCTCTTCAAAGTTCGT }\end{array}$ & 53 & 386 & 30 \\
\hline h1-calponin & $\begin{array}{l}\text { ACTGTGACACGCTCAACGTC } \\
\text { GTGCTTCCTTTGGGTGTTGT }\end{array}$ & 59 & 410 & 35 \\
\hline Osterix & $\begin{array}{l}\text { GCAAGGCTTCGCATCTGAA } \\
\text { TAGCAGGTTGCTCTGCTC }\end{array}$ & 55 & 370 & 30 \\
\hline OCN (osteocalcin) & $\begin{array}{l}\text { AACGGTGGTGCCATAGATGC } \\
\text { AGGACCCTCTCTCTGCTCAC }\end{array}$ & 59 & 293 & 30 \\
\hline Runx2 & $\begin{array}{l}\text { AGTCCCAACTTCCTGTGCT } \\
\text { GTGTCATCATCTGAAATACGC }\end{array}$ & 58 & 689 & 35 \\
\hline$\beta$-Actin & $\begin{array}{l}\text { AGCCATGTACGTAGCCATCC } \\
\text { TCTCAGCTGTGGTGGTGAAG }\end{array}$ & 60 & 226 & 21 \\
\hline
\end{tabular}

graded ethanol series described above, the specimens were immersed in a 1:1 solution of $100 \%$ ethanol and ether for 1 day. They were then incubated in a $2 \%$ solution of Ceducol (Merck, Darmstadt, Germany) in a 1:1 solution of $100 \%$ ethanol and ethyl ether for 2 days, $4 \%$ celloidin solution for 2 days, and then $8 \%$ celloidin solution for 2 days. The specimens were then immersed in a 10:3 mixture of $70 \%$ ethanol and $100 \%$ chloroform for $1-3$ days. After hardening of the celloidin solution, the block was sectioned on a Reichert-Jung Mod.Hn40 microtome (Leica Instruments, Nussloch, Germany) set at $50 \mu \mathrm{m}$. Sections were hydrated in a graded ethanol series and then lemosole containing a small amount of phenol (1-3 min each), and then mounted on glass slides and covered with Softmount coverslips (Wako). Fluorescence signals from the labelled cell structure were detected using a fluorescence microscope, as described above.

Immunofluorescence of Cultured Cells and

Paraffin-Embedded Sections

For immunofluorescence analysis of cultured cells, cells were subcultured in individual wells of type I collagen-coated 8-cham- 
ber slides at a density of $1 \times 10^{4}$ cells/well (BD Biosciences, Franklin Lakes, N.J., USA) for 2 days. Cells were then fixed in $4 \%$ paraformaldehyde for $30 \mathrm{~min}$ and permeabilised with $0.2 \%$ Triton X-100 in PBS. After background inhibition with 3\% (w/v) bovine serum albumin in PBS, cells were labelled with anti-vWF rabbit polyclonal antiserum (1:200; Dako, Carpinteria, Calif., USA), anti-h1-calponin mouse monoclonal antibody (clone hCP, 1:300; Sigma), or anti-Tie-2 rabbit polyclonal antibody (1:50; Santa Cruz Biotechnology Inc., Santa Cruz, Calif., USA) at room temperature for $1 \mathrm{~h}$, and then at $4^{\circ} \mathrm{C}$ overnight. After washing with $0.2 \%$ Triton X-100 in PBS to remove the primary antibody, the cells were incubated with Alexa Fluor ${ }^{\circledR} 488$-conjugated goat anti-rabbit IgG or Alexa Fluor 488-conjugated rabbit anti-mouse IgG (1:1,000; Molecular Probes, Leiden, The Netherlands) for 30 min at room temperature. After washing with $0.2 \%$ Triton X-100 in PBS to remove the secondary antibody, the cells were labelled with DAPI and Alexa Fluor 594 phalloidin $(6.6 \mu \mathrm{M}$; Invitrogen, Paisley, UK). The fluorescent signal was detected using a fluorescence microscope.

For immunofluorescence analysis of cells in paraffin-embedded sections, the sections were treated with $0.1 \%$ trypsin in PBS for $30 \mathrm{~min}$ at $37^{\circ} \mathrm{C}$. Cells were first labelled with anti-Tie-2 rabbit polyclonal antibody (1:50; Santa Cruz Biotechnology Inc.). Second, the cells were incubated with Alexa Fluor 488conjugated rabbit anti-mouse IgG (1:1,000; Molecular Probes) and, finally, the nuclei and actin fibres in the cells were labelled with DAPI and Alexa Fluor 594 phalloidin (6.6 $\mu \mathrm{M}$; Invitrogen), respectively.

\section{Western Blotting}

Cells were lysed in $25 \mathrm{~mm}$ Tris- $\mathrm{HCl}$ (pH 6.5), 1\% SDS, and 5\% glycerol by boiling for $5 \mathrm{~min}$. Equal amounts of protein from each cell lysate were separated in a $10 \%$ Tris-glycine SDS-polyacrylamide-gel electrophoresis gel. The separated proteins were transferred onto PVDF membranes (Millipore Corp., Bedford, Mass., USA) and incubated for $1 \mathrm{~h}$ at room temperature in blocking solution $(5 \%(\mathrm{w} / \mathrm{v})$ bovine serum albumin in PBS). The membranes were then incubated in blocking solution containing anti-p44/42 MAPK rabbit polyclonal antibody (1:1,000; Cell Signaling, Danvers, Mass., USA) or anti-phospho-p44/42 MAPK rabbit polyclonal antibody (1:1,000; Cell Signaling) at $4^{\circ} \mathrm{C}$ overnight. Membranes were washed and incubated with a 1:5,000 dilution of horseradish peroxidase-conjugated anti-rabbit IgG affinity purified goat antibody (Chemicon International Inc., Temecula, Calif., USA) for $40 \mathrm{~min}$ at room temperature. Peroxidase activity on the membrane was visualised using the ECL Western blotting detection system (Amersham Biosciences Corp., Piscataway, N.J., USA), in accordance with the protocol provided by the manufacturer.

\section{Cell Proliferation Assay}

Cell proliferation was assessed as a function of NADH content using a TetraColor ONE [5 mM (2-(2-methoxy-4-nytrophenyl)-3(4-nitro-phenyl)-5-(2,4-disulphphenyl)-2H-tetrazolium, monosodium salt); $0.2 \mathrm{mM}$ 1-methoxy-5-methylphenazinium methylsulphate; and $150 \mathrm{~mm} \mathrm{NaCl}$ ]-based assay, according to the manufacturer's instructions (Seikagaku Inc., Nihonbashi, Tokyo) [22]. Briefly, cells $\left(1.5 \times 10^{4}\right.$ cells /well in 96-well plates) were incubated for the times indicated with the selected concentration of U0126 or LY294002 in the culture medium. Ten microlitres of
TetraColor ONE solution was then added to each well, and the cells were incubated for $2 \mathrm{~h}$. The absorbance of each well was then determined at a wavelength of $450 \mathrm{~nm}$, with background subtraction at $630 \mathrm{~nm}$. The data were statistically analysed by the Student $t$ test, and a value of $\mathrm{p}<0.05$ was considered as significant. The data are presented as the mean \pm SD of triplicate determinations.

Detection of Apoptotic Cells by TUNEL

The TdT-mediated dUTP nick end-labelling (TUNEL) assay [23] was performed using the DeadEnd ${ }^{\mathrm{TM}}$ Colorimetric TUNEL System to detect nuclear apoptosis, according to the manufacturer's instructions (Promega, Madison, Wisc., USA). This system labels the ends of fragmented DNA present in apoptotic cells. Briefly, SCDC2 cells were subcultured in each well of type I collagen-coated 8-chamber slides at a density of $1 \times 10^{4}$ cells/well (BD Biosciences) for 2 days, and then some cells were treated with LY294002 (20 mM) for $24 \mathrm{~h}$. The cells were then fixed with $4 \%$ paraformaldehyde for $30 \mathrm{~min}$, and apoptotic cells were labelled using the TUNEL assay. Finally, the labelled cells were viewed under a light microscope.

\section{Results}

\section{Morphological Characterisation of Rat PDL Fibroblasts}

A primary culture of rat PDL fibroblasts was established and 4 SCDCs (SCDC1-4) were obtained from the primary culture as described in Materials and Methods. As shown in figure 1, primary rat PDL fibroblast (fig. 1a) and SCDC (fig. 1b-e) cultures have a fibroblastic spindle shape.

\section{Expression of MSC Markers and PDL-Related Genes in Rat PDL Fibroblasts}

RT-PCR analysis revealed that the cultured primary PDL fibroblasts and all 4 SCDCs consistently expressed mRNA for MSC markers, that is, CD44, VCAM1, SM $\alpha-$ actin and ALP [24-28], although slight differences in their expression levels were observed. In contrast, CD146 is not consistently expressed in the cultured primary PDL fibroblasts and SCDCs: SCDC1 vigorously expressed CD146 but the cultured primary PDL fibroblasts and the other SCDCs not (fig. 2a). On the other hand, SCDCs consistently expressed mRNAs for extracellular matrix proteins of PDL, that is, $\alpha 1$ (I) procollagen, OPN and periostin [15], although slight differences in their expression levels were observed (fig. 2b). Recent reports have also shown that PDL fibroblasts express scleraxis, a specific marker for tendons and ligaments [7, 29]. All 4 SCDCs also expressed scleraxis mRNA, although slight differences in expression levels were observed. These observa- 

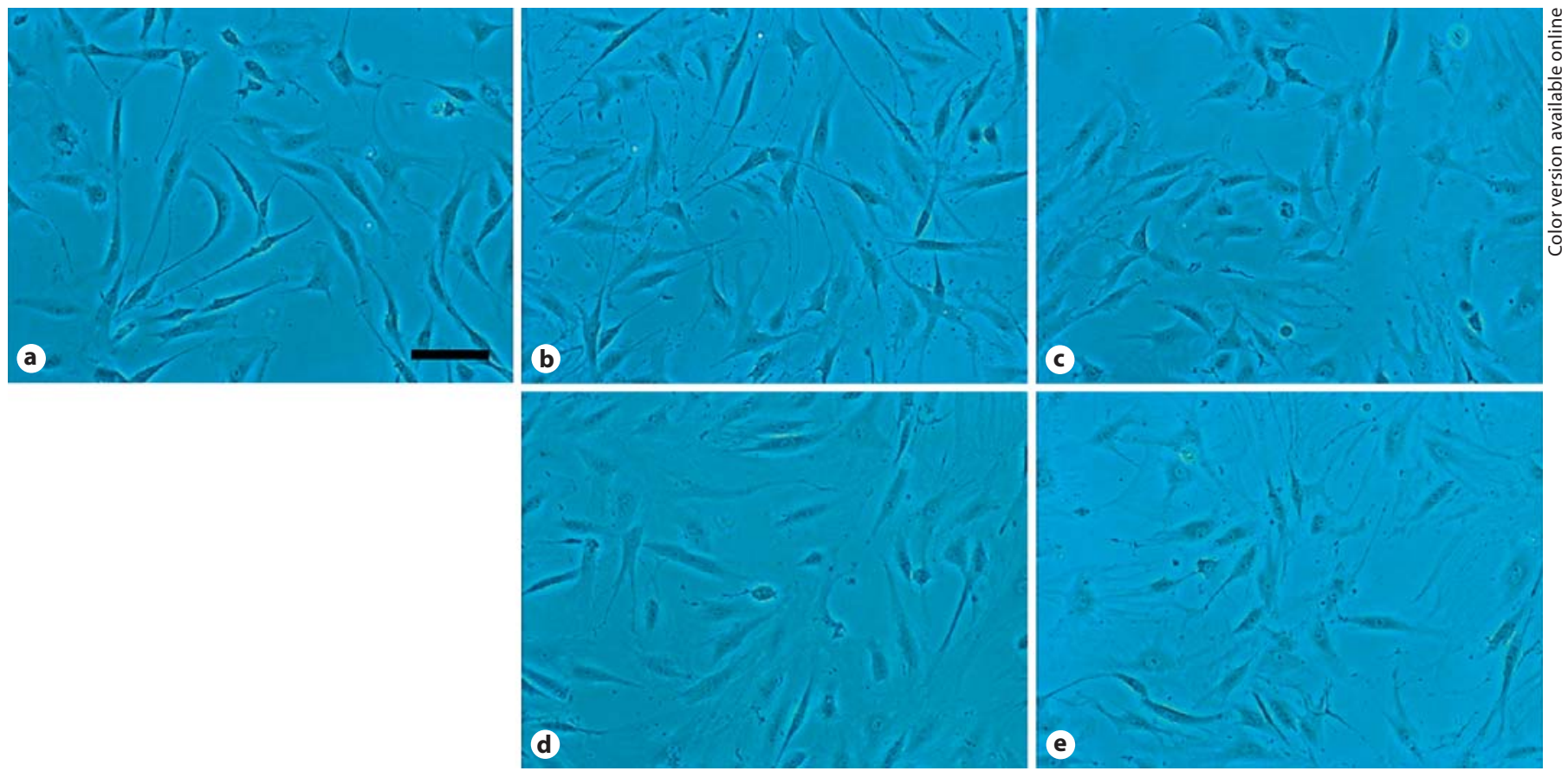

Fig. 1. Morphological characterisation of rat PDL fibroblasts. Rat PDL fibroblasts were cultured on type I collagen-coated plastic plates and viewed by phase-contrast microscopy. a Primary cul- ture of rat PDL fibroblasts. b-e SCDCs obtained from cultured primary PDL fibroblasts. b SCDC1; c SCDC2; d SCDC3; e SCDC4. Scale bar $=100 \mu \mathrm{m}$. tions indicate that these cells possess characteristics of both undifferentiated mesenchymal cells and PDL fibroblasts.

\section{Simultaneous Expression of EC and SMC Markers by SCDCs}

We examined the mRNA expression of vascular cell markers by RT-PCR analysis. As shown in figure 3a, mRNAs for the EC markers Tie-2, Flk-1, vWF and CD31 were expressed by all 4 SCDCs, although considerable differences in Tie-2 and CD31 expression levels were observed. Tie-2 mRNA was abundantly expressed in SCDC2, but was nearly undetectable in the other SCDCs. CD31 mRNA was abundantly expressed in SCDC4, moderately expressed in SCDC2, and expressed at very low levels in SCDC1 and -3. In contrast, mRNA for the definitive EC marker Flk-1 was abundantly expressed in SCDC2 and moderately expressed in SCDC3 cells, but was not expressed in $\mathrm{SCDC1}$ and -4. In addition, as shown in figure $3 \mathrm{~b}, \mathrm{mRNAs}$ for the SMC markers h1-calponin and smoothelin were consistently expressed in all 4 SCDCs. Thus, SCDCs simultaneously expressed both EC and SMC markers.
Construction of Vessel-Like Structures in the Type I Collagen Scaffold by PDL Fibroblasts

Abundantly Expressing EC Markers, but Not by Cells Demonstrating Abundant Expression of Osteoblast Markers

We evaluated the ability of SCDCs to construct a capillary tube-like structure resembling microvasculature and examined the angiogenic activity of SCDC1 and SCDC2 cells. As shown in figure 3a, SCDC2 cells exhibited EClike characteristics in that they demonstrated abundant expression of the various EC-specific markers, unlike SCDC1 cells. As shown in figure 4b, SCDC2 cells formed tight spheroidal aggregates, unlike SCDC1 cells, which displayed loose cell clusters around which many isolated cells were scattered (fig. 4a). The spheroidal aggregates were then embedded in a type I collagen scaffold and the angiogenic activity of SCDC1 and SCDC2 cells was compared. As shown in figure $4 \mathrm{~d}, \mathrm{SCDC} 2$ cells formed many microvasculature-like structures originating from the entire surface of the spheroid body. In contrast, SCDC1 cells formed only a few thin, tube-like structures originating from the loose cell clusters (fig. 4c). 


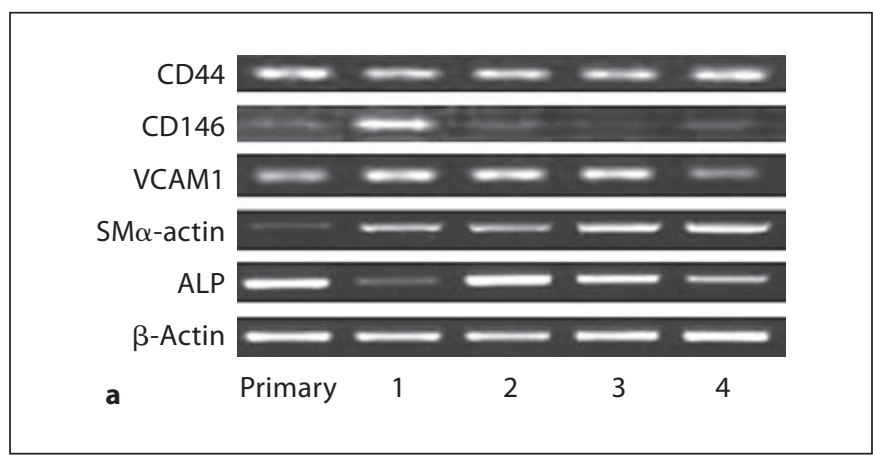

Fig. 2. Expression of MSC markers and PDL-related genes in rat PDL fibroblasts. RT-PCR analyses were performed using specific primers for genes expressed in MSCs (a) or ligament fibroblasts (b). Cells obtained from cultured primary rat PDL (lane 1), SCDC1 (lane 2), SCDC2 (lane 3), SCDC3 (lane 4) and SCDC4 (lane 5) were plated in type I collagen-coated $6-\mathrm{cm}$ cell culture dishes at $3 \times 10^{4}$ cells $/ \mathrm{cm}^{2}$ and cultured for $72 \mathrm{~h}$. Total cellular RNA was

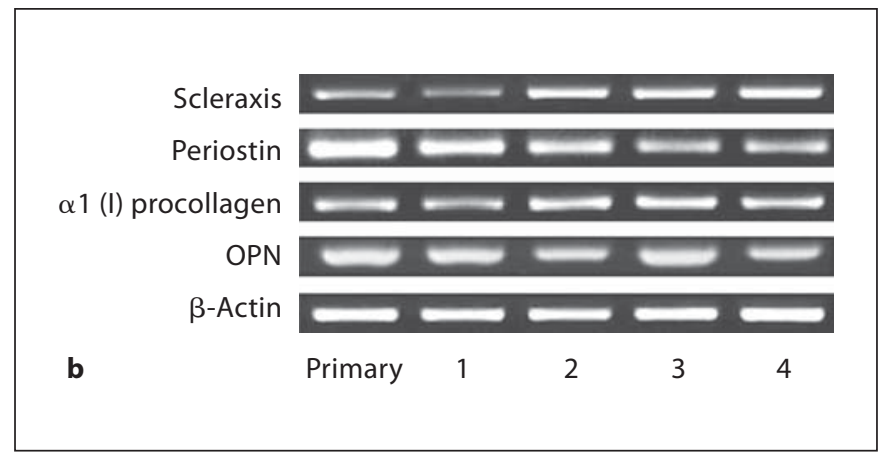

extracted and RT-PCR was performed to examine the levels of mRNA expression. The PCR products were separated in a $2 \%$ agarose gel containing ethidium bromide and observed using an ultraviolet transilluminator. Equal loading of cDNA samples was confirmed by amplification of $\beta$-actin cDNA. Data represent 1 of 3 independent experiments with similar results.
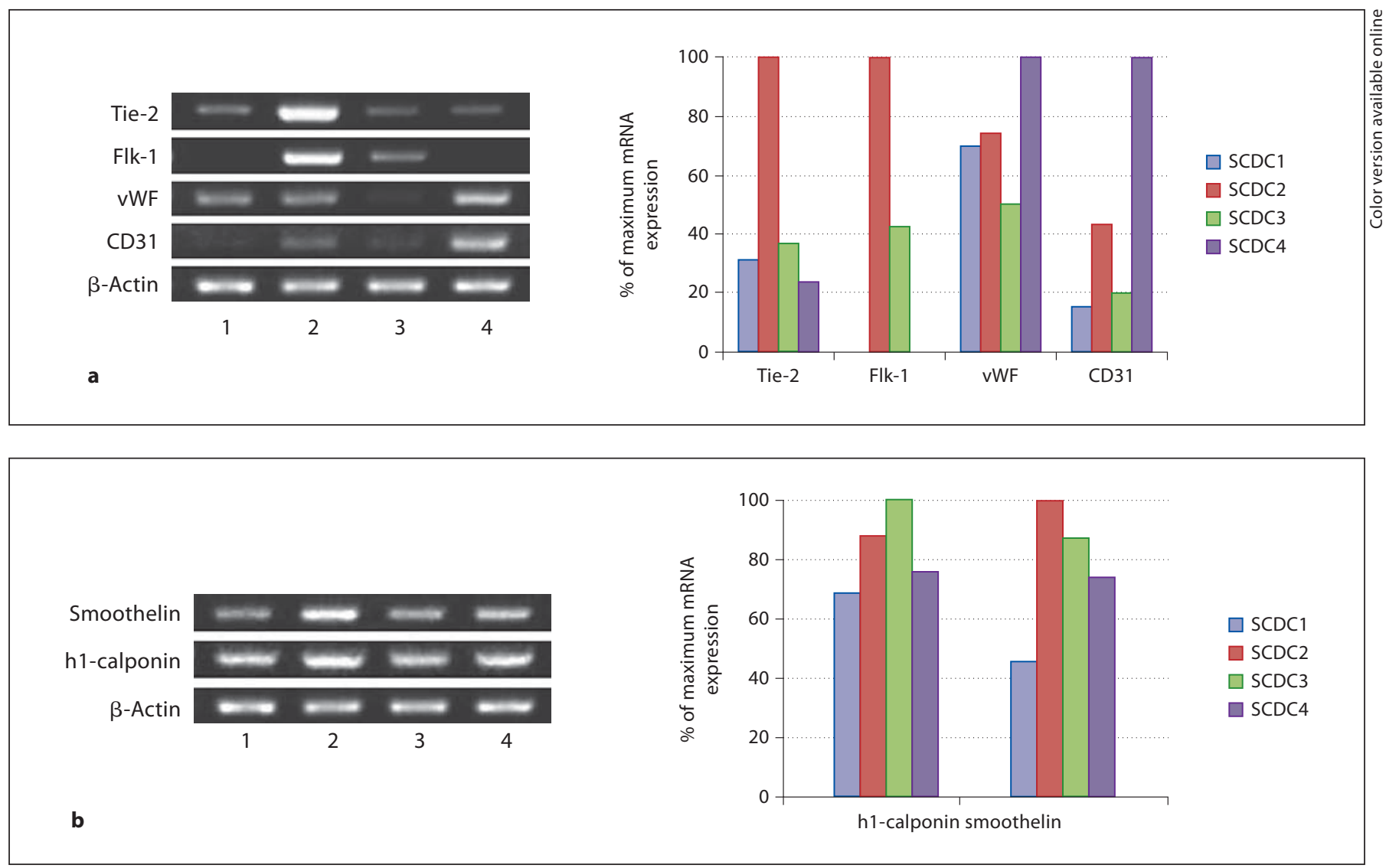

Fig. 3. Simultaneous expression of EC and SMC markers by SCDCs. RT-PCR analyses were performed using specific primers for markers of (a) ECs and (b) SMCs. Cells from SCDC1 (lane 1), -2 (lane 2), -3 (lane 3), and -4 (lane 4) were plated and cultured as described in the legend of figure 2. The right panels represent mRNA expression standardised as a ratio with respect to $\beta$-actin mRNA. 

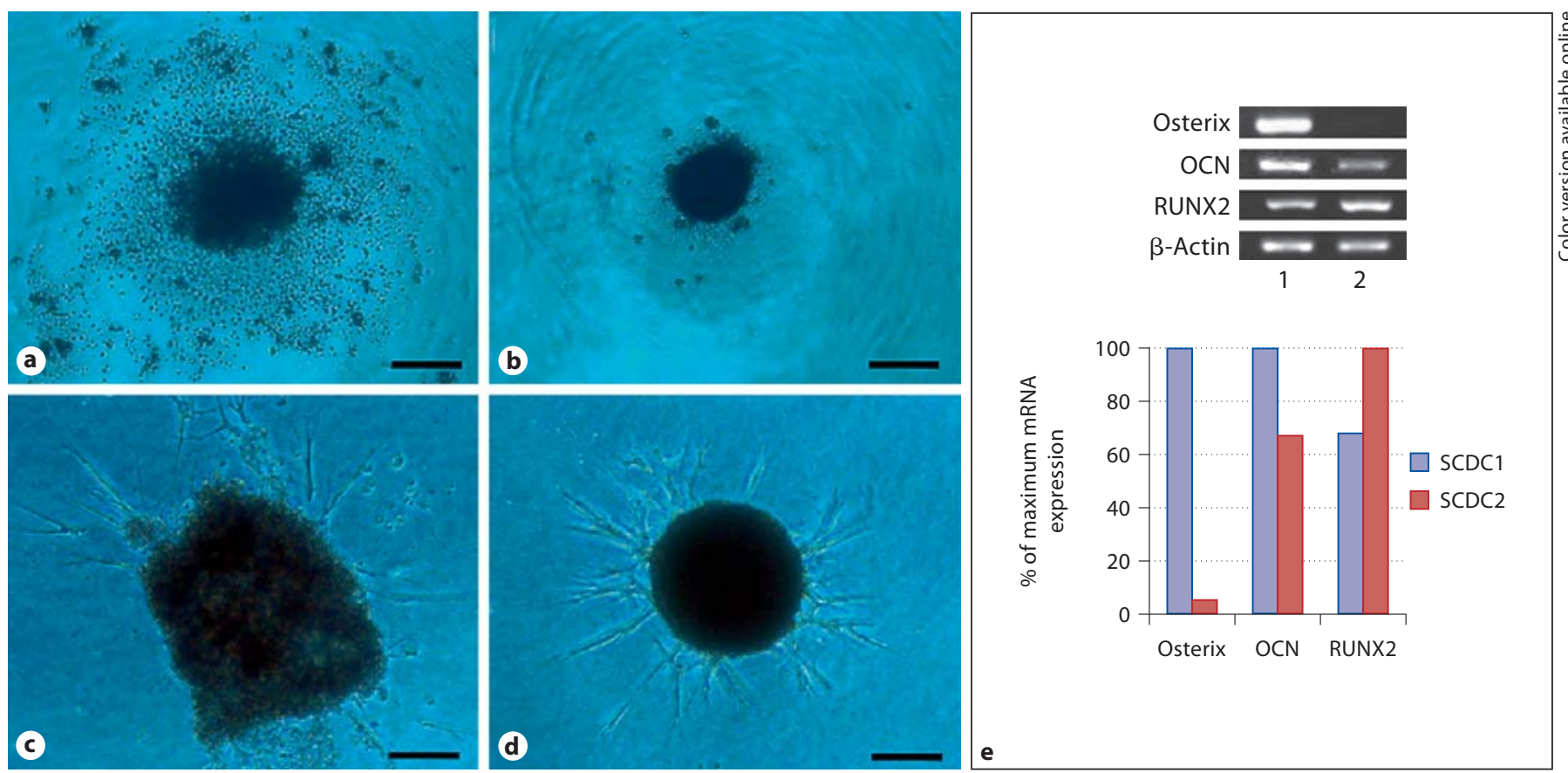

Fig. 4. Construction of vessel-like structures in the type I collagen scaffold by PDL fibroblasts abundantly expressing EC markers, but not by cells demonstrating abundant expression of osteoblast markers. To compare the ability of SCDC1 (a, c) and SCDC2 (b, d) to construct a tube-like structure, a cell cluster resembling a spheroid aggregate was constructed by each $\operatorname{SCDC}(\mathbf{a}, \mathbf{b})$, as described in Materials and Methods. The cell cluster was then embedded in the type I collagen gel. After culturing for $30 \mathrm{~h}$, the morphological characteristics of the embedded cell cluster were viewed by phase-contrast microscopy. SCDC2 vigorously constructed many thick, tube-like structures from the surface of the cell cluster (d), whereas SCDC1 constructed only a few thin, fibrelike structures (c). Scale bars are $100 \mu \mathrm{m}(\mathbf{a}, \mathbf{b})$ and $50 \mu \mathrm{m}(\mathbf{c}, \mathbf{d})$. e RT-PCR analyses were performed using specific primers for markers of osteoblasts. Cells from SCDC1 (lane 1) and SCDC2 (lane 2) were plated and cultured as described in the legend of figure 2. The right panels represent mRNA expression standardised as a ratio with respect to $\beta$-actin mRNA (e).
We previously reported that bone morphogenetic protein, which induces the expression of osteoblast differentiation markers in PDL fibroblasts, clearly suppresses EC marker expression in cells [8]. Based on these results, it seems reasonable to speculate that the expression of an osteoblastic phenotype attenuates that of the EC-like phenotype in PDL fibroblasts. Therefore, we compared the expression levels of osteoblast markers between SCDC1 and SCDC2 cells. Intriguingly, SCDC1, but not SCDC2, demonstrated abundant expression of the definitive osteoblast markers osterix and OCN (fig. 4e).

\section{Construction of a Mature Vessel-Like Structure with a Lumen}

To evaluate the morphological details of the capillary tube-like structure, we obtained paraffin sections of SCDC2 in the type I collagen scaffold. As shown in figure $5 \mathrm{a}-\mathrm{d}$, the basal part of the tube-like structure originating from spheroidal aggregates of SCDC2 cells was longitudi- nally sectioned. A lumen-like cavity (red arrows) was clearly observed between two wall-like structures (blue arrows) constructed by SCDC2 cells. Cross sections of the tube-like structure revealed several ring-like structures with a lumen in three serial sections (red arrows; fig. 5e-j).

A three-dimensional image of the vessel-like structure in a celloidin section (50 $\mu \mathrm{m}$ thick) was constructed using the fluorescence microscope. Vessel-like structures sprouted from the surface of the spheroidal aggregates in various directions (fig. $6 \mathrm{a}-\mathrm{c}$ ). As shown in figure $6 \mathrm{~d}-\mathrm{m}$, ring-like structures constructed by SCDC2 cells were observed in serial cross sections throughout the vessel-like structure.

Expression of Definitive EC and SMC Marker Proteins in SCDC2 Cells

SCDC2 cells cultured on type I collagen-coated glass slides were stained using anti-vWF polyclonal antibody (green) (fig. 7b) and anti-h1-calponin (green) (fig. 7c). 

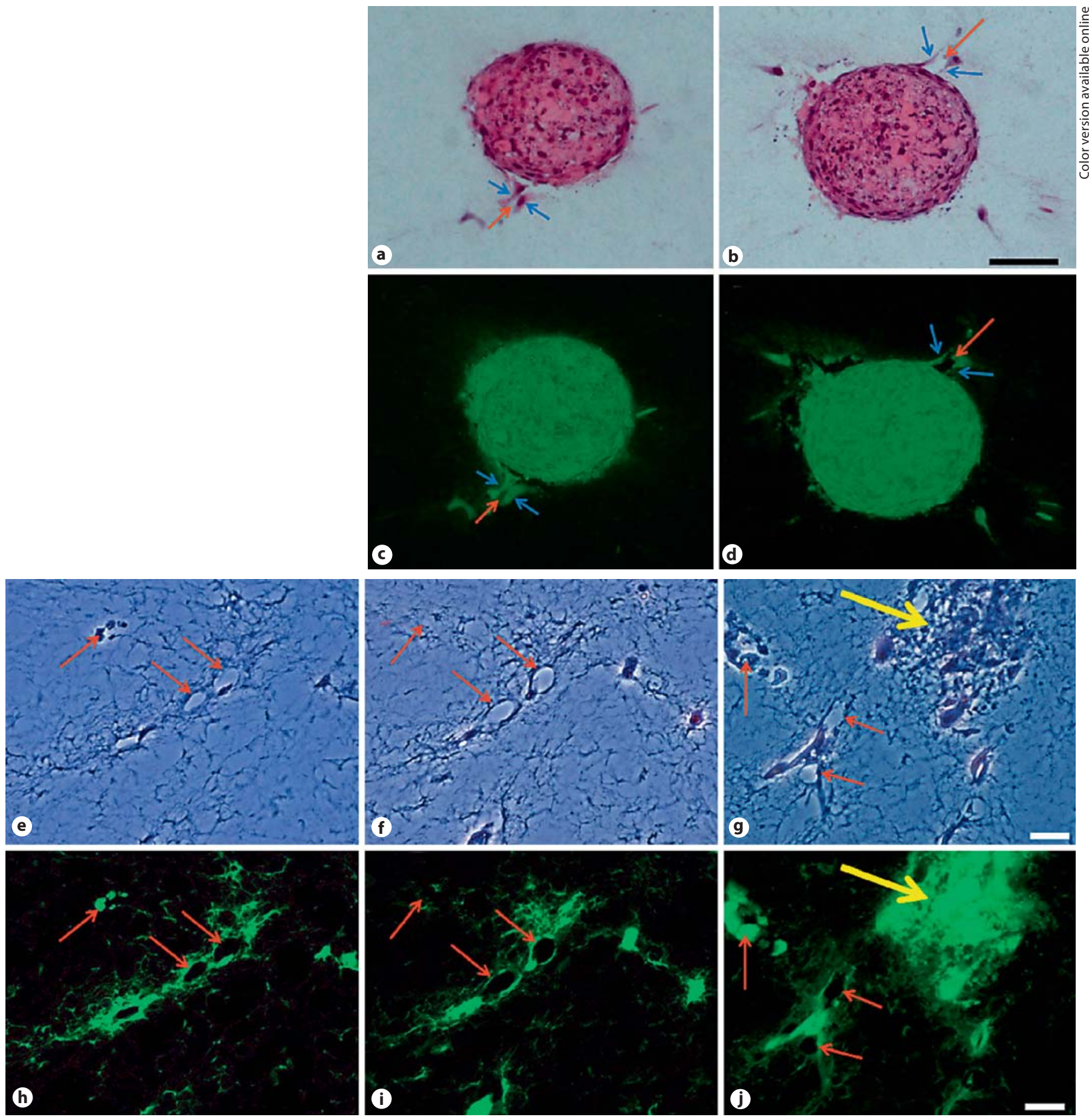

Fig. 5. Construction of a mature vessel-like structure with a lumen. The tube-like structures and cell clusters constructed by SCDC2 cells were morphologically evaluated using a fluorescence microscope. a-d A three-dimensional culture of green fluorescence-stained cells in a type I collagen gel was fixed and embedded in a paraffin block as described in Materials and Methods. The paraffin sections were stained with haematoxylin-eosin and viewed under a light microscope (a, b) or a fluorescence microscope $(\mathbf{c}, \mathbf{d})$. Red arrows indicate portions of longitudinal sections

present in basal parts of the vessel-like structures that protruded from the surface of the cell cluster. Scale bar $=50 \mu \mathrm{m}$. e-j Red arrows indicate portions of cross sections of vessel-like structures protruding from the cell cluster. $\mathbf{e - g}$ Haematoxylin-eosin-stained paraffin sections. $\mathbf{h}-\mathbf{j}$ Fluorescence signals from the same sections as those shown in $\mathbf{e - g}$. The lumen of a vessel-like structure was observed in 3 serial sections ( $5 \mu \mathrm{m}$ thick). Yellow arrows indicate parts of the cell cluster body. Scale bars $=20 \mu \mathrm{m}$. 


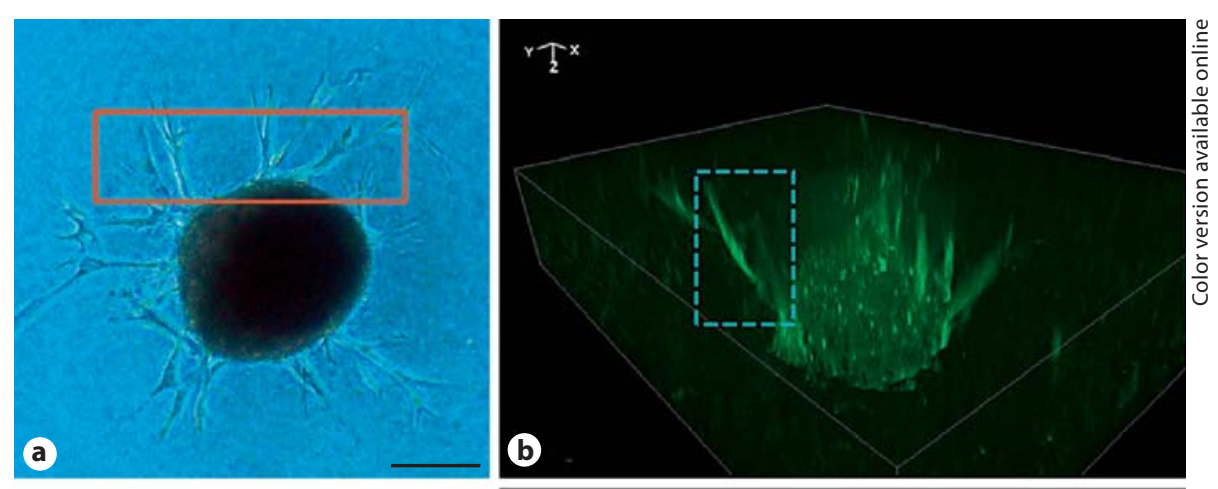

Fig. 6. Three-dimentional images of cross sections throughout the vessel-like structure constructed by SCDC2 cells. a The three-dimensional images of vessel-like structures in celloidin sections $(50 \mu \mathrm{m}$ thick) were constructed using a fluorescence microscope. The red rectangle indicates the outline of the fluorescencescanned parts of the vessel-like structure and the cell cluster shown in $\mathbf{b}-\mathbf{m}$. $\mathbf{b}$ and $\mathbf{c}$ are three-dimensional views of vessel-like structures protruding from the surface of the cell cluster at different angles. $\mathbf{d}$ and $\mathbf{e}$ are magnified images of the areas enclosed within the dashed blue rectangle in $\mathbf{b}$ and c, respectively. $\mathbf{f}-\mathbf{m}$ Images of cross sections throughout the vessel-like structure in d. Scale bars are $50 \mu \mathrm{m}$ (a) and $10 \mu \mathrm{m}$ (b-m).

Nuclei and actin fibres in SCDC2 cells were stained with DAPI (blue) and phalloidin (red) in figure $7 \mathrm{a}-\mathrm{c}$, respectively. No green fluorescent signal was detected in SCDC2 cells labelled with secondary antibodies only (fig. 7a). As shown in these panels, the protein expression of $\mathrm{vWF}$ and h1-calponin in SCDC2 cells was confirmed. Moreover, SCDC2 cells cultured on glass slides expressed these cellspecific markers simultaneously (data not shown).
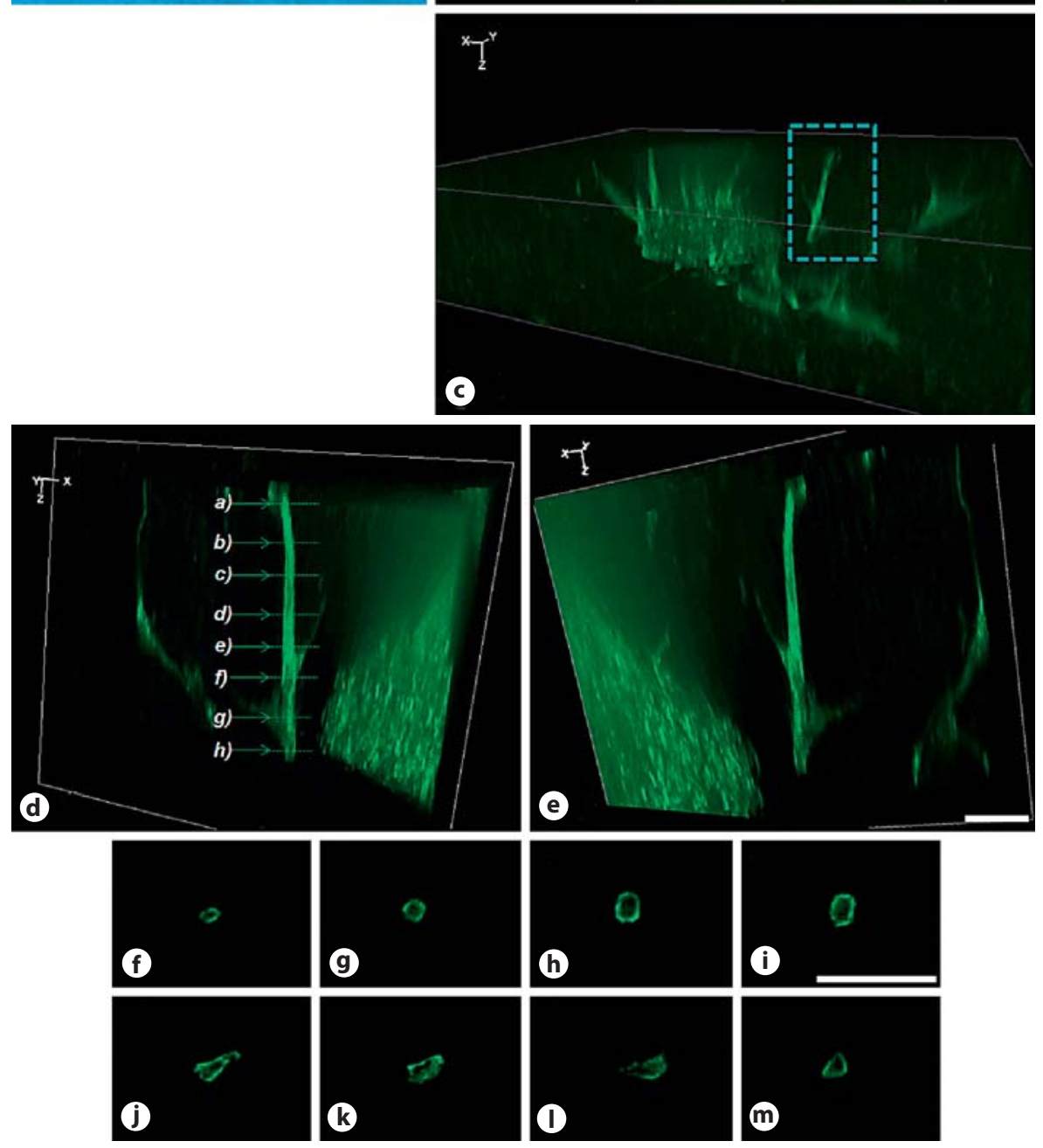

Construction of Definitive EC Marker Tie-2-Positive Vessel-Like Structures in the Type I Collagen Scaffold SCDC1 and SCDC2 cells cultured on type I collagencoated glass slides were stained using anti-Tie-2 polyclonal antibody (green) (fig. 8a, b). Nuclei and actin fibres in the cells were stained with DAPI (blue) and phalloidin (red), as indicated in figure $8 \mathrm{a}$ and $\mathrm{b}$, respectively. As shown in figure $8 \mathrm{a}$, Tie- 2 protein expression (green) was 

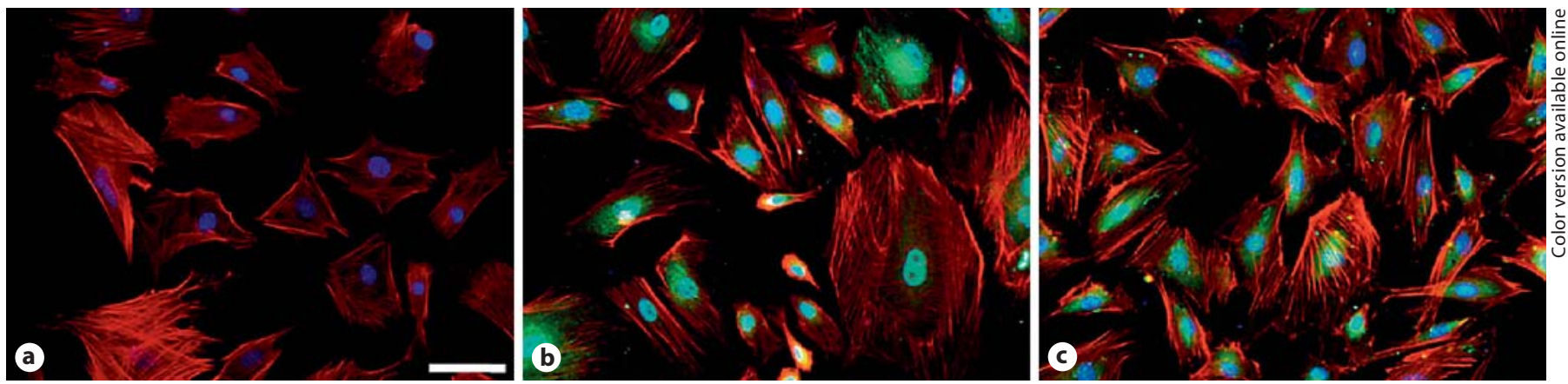

Fig. 7. Expression of definitive EC and SMC marker proteins in SCDC2 cells. SCDC2 cells were plated on type I collagen-coated glass slides at a density of $1 \times 10^{4}$ cells/well, cultured for 2 days, and fixed for immunocytochemical examination. $\mathbf{a}$ In the $\mathrm{ab}$ sence of primary antibodies against either vWF or h1-calponin, but with fluorescently labelled secondary antibodies against rab-

bit and mouse IgG (green); $\mathbf{b}$ in the presence of primary antibody against vWF and fluorescently labelled secondary antibody against rabbit IgG (green); $c$ in the presence of primary antibody against h1-calponin and fluorescently labelled secondary antibody against mouse IgG (green). a-c The cells were stained with both phalloidin (red) and DAPI (blue). Scale bar $=50 \mu \mathrm{m}$.
Fig. 8. Construction of a definitive EC marker Tie-2-positive vessel-like structure in a type I collagen scaffold. Cultured SCDC1 (a) and SCDC2 (b) were immunocytochemically evaluated with an antiTie-2 antibody. The cells were simultaneously stained with anti-Tie-2 antibody (green), phalloidin (red) and DAPI (blue). c, $\mathbf{d}$ The tube-like structures and cell clusters constructed by SCDC2 cells were immunohistochemically evaluated with an anti-Tie-2 antibody. In c, paraffin sections of the three-dimensional culture of SCDC2 cells were stained with anti-Tie-2 antibody (green). In d, paraffin sections of the threedimensional culture of SCDC2 cells were simultaneously stained with anti-Tie-2 antibody (green), phalloidin (red) and DAPI (blue). Scale bar $=50 \mu \mathrm{m}$.
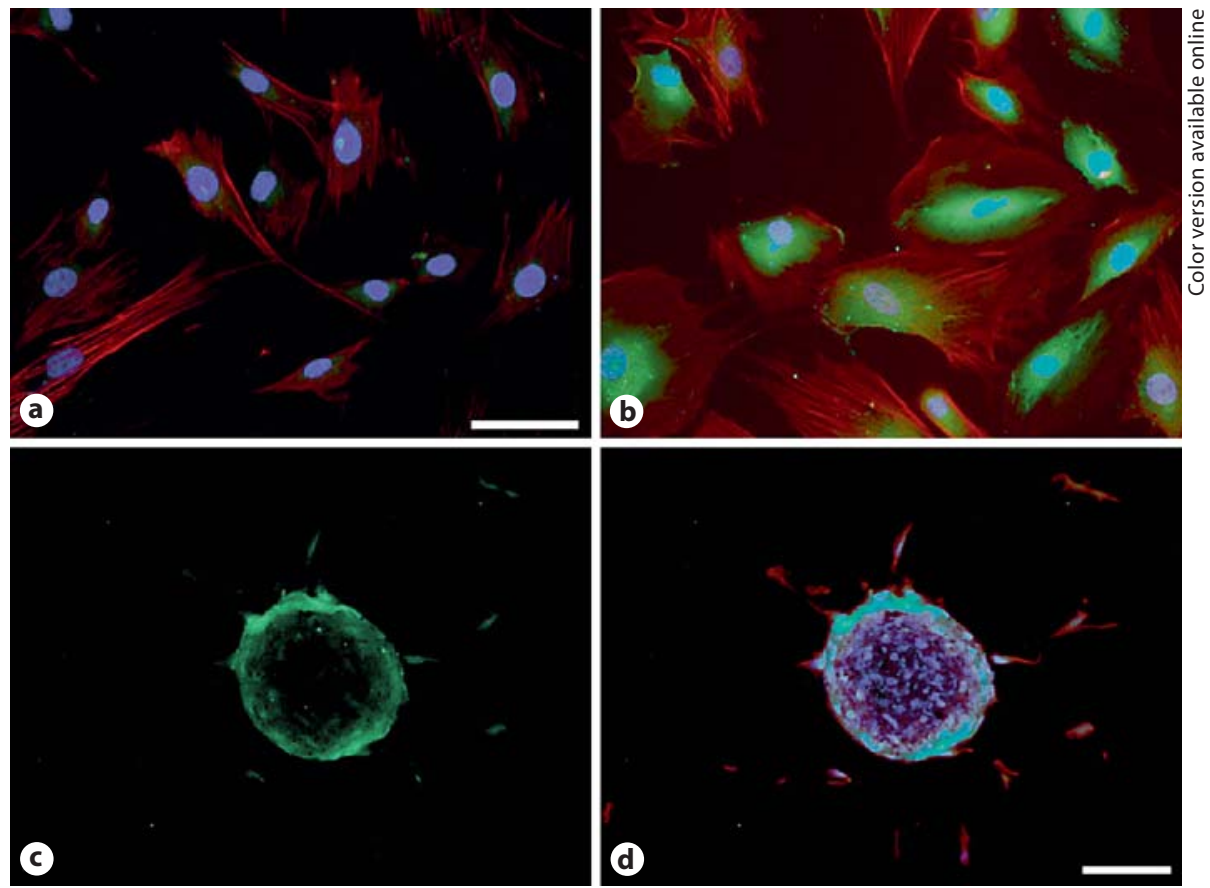

not detectable in SCDC1 cells expressing a very low amount of Tie-2 mRNA (fig. 3a). In contrast, SCDC2 cells, which expressed abundant Tie-2 mRNA (fig. 3a), clearly expressed Tie- 2 protein around the cell membrane and in the cytoplasm (fig. 8b). Although Tie-2 expression must be within cell membrane, Tie-2 expression in SCDC2 cells was observed within cytoplasm than cell membrane in figure $8 \mathrm{~b}$. Most of Tie- 2 receptors might be endocytosed and internalized into SCDC2 cells: Bogdanovic et al. [30] reported that around $70 \%$ of Tie- 2 within cell membrane was rapidly internalized into the human umbilical vascular endotherial cells within $30 \mathrm{~min}$ after stimulation with Tie-2 ligands, angiopoietin (Ang)-1. Because RT-PCR analysis revealed that SCDC2 actually expressed Ang-1 (data not shown), it seemed reasonable to suppose that Ang-1 stimulated Tie-2 receptors in an au- 

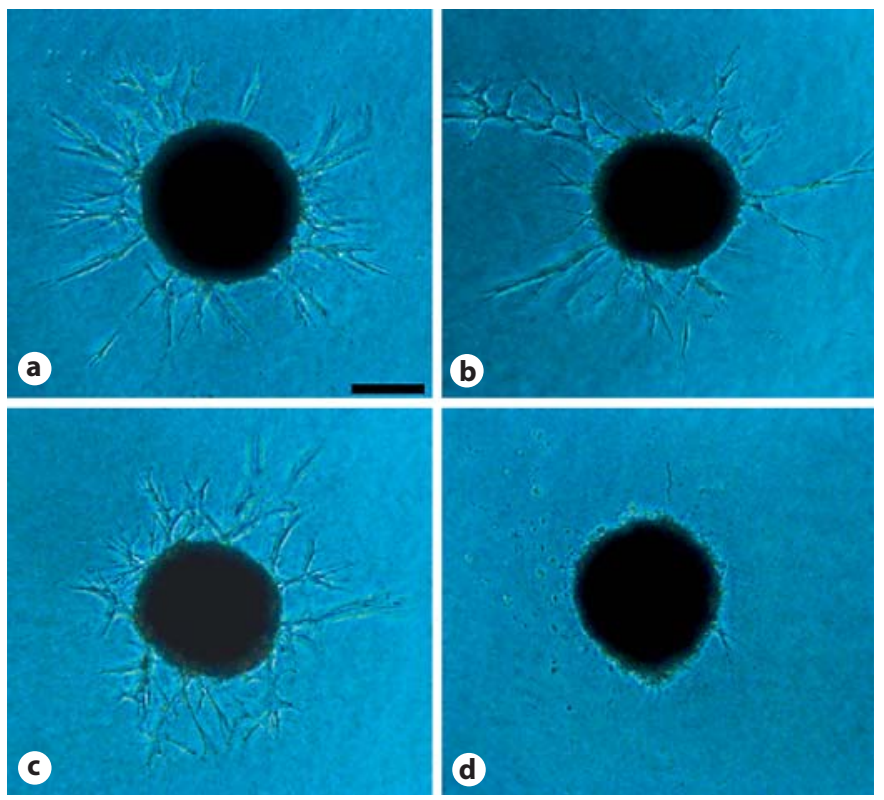

No additives

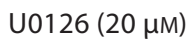

Vehicle $(0.2 \%$ DMSO)

LY294002 (20 $\mu \mathrm{M})$
Fig. 9. Association of $\mathrm{PI} 3 \mathrm{~K}-$ dependent intracellular signalling with angiogenic activity in SCDC2 cells. We evaluated whether the MAPK/MEK and PI3K/Akt signalling pathways in SCDC cells are important for angiogenic activity. The MEK inhibitor U0126 or PI3K inhibitor LY294002 was added to a three-dimensional culture of SCDC2 cells. No additives (a), vehicle $(0.2 \%$ DMSO) (b), 20 mM U0126 (c) or 20 mM LY294002 (d). The vessellike structure was viewed by phase-contrast microscopy. Scale bar $=50 \mu \mathrm{m}$. In e, the status of SCDC2 cell proliferation was assessed as a function of NADH reductase activity. The percent proliferation was calculated using the following formula: percent proliferation $=100 \times\left(\mathrm{A}^{450-630 \mathrm{~nm}}\right.$ with each additive $/ \mathrm{A}^{450-630 \mathrm{~nm}}$ without additives). Data are expressed as means \pm SD of 3 independent experiments. ${ }^{*} \mathrm{p}<0.05$ compared to the control. In $\mathbf{f}$, RT-PCR analyses were performed using specific primers for EC markers. SCDC2 cells were plated and cultured as described in the legend of figure 2. Right panels represent mRNA expression standardised as a ratio with respect to $\beta$-actin $\mathrm{mRNA}$.

tocrine fashion in SCDC2 cells resulting in the internalization of Tie- 2 .

Next, we evaluated Tie-2 expression in the vessel-like structure in the three-dimensional type I collagen scaffold. The vessel-like structure and spheroidal aggregates composed of SCDC2 cells in paraffin-embedded sections were labelled with anti-Tie-2 polyclonal antibody (green).
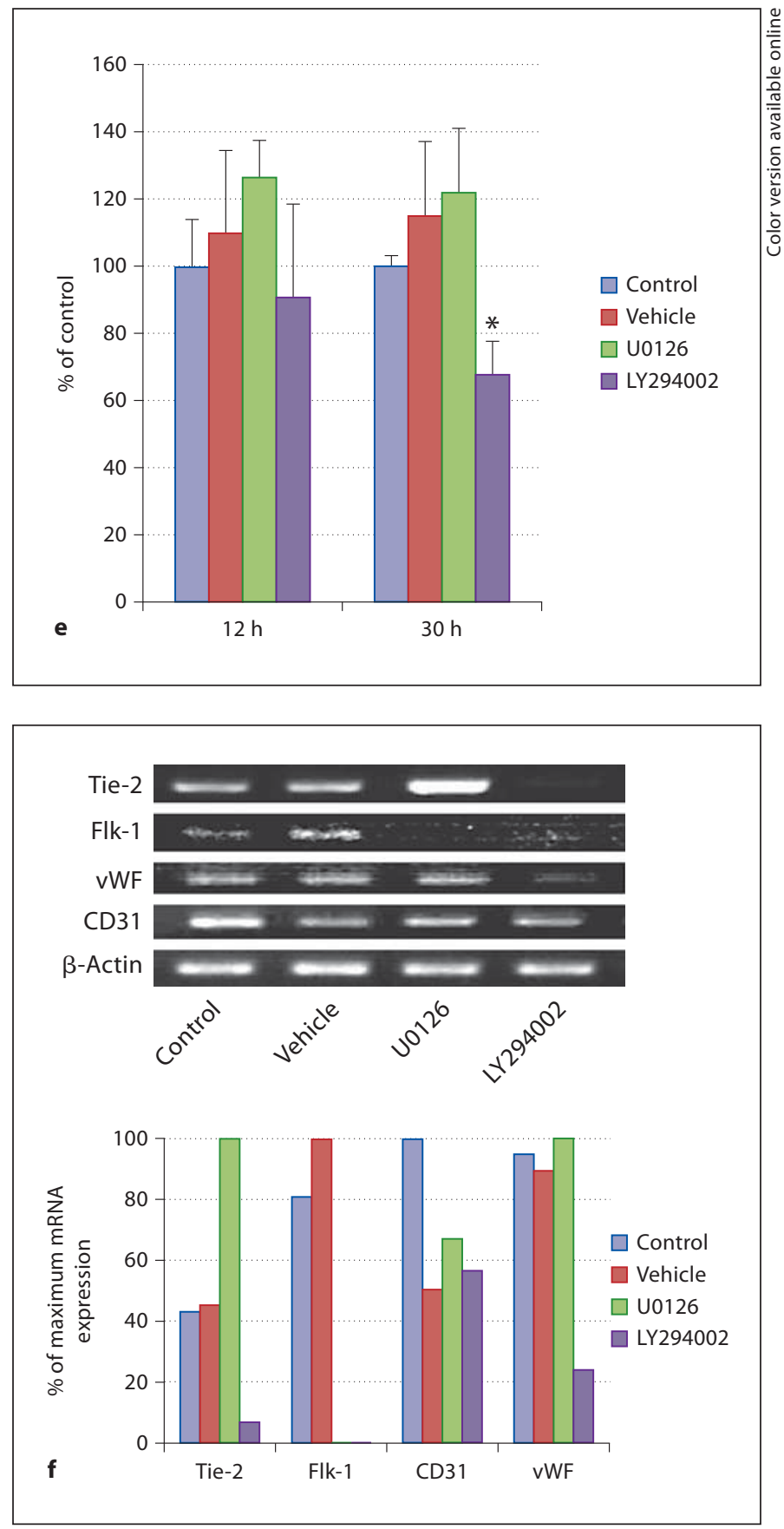

As shown in figure $8 \mathrm{c}$, Tie-2 expression was clearly detected in the vessel-like structure or around the edge of the SCDC2 spheroid. However, no Tie-2 expression was detected around the centre of the spheroidal aggregates. In addition, no Tie- 2 expression was detected in the capillary-like structure from the SCDC1 spheroid or in the SCDC1 spheroid (data not shown). 
Association of PI3K-Dependent Intracellular

Signalling with Angiogenic Activity in SCDC2 Cells

To evaluate the effects of MAPK/MEK- and PI3K/Aktdependent intracellular signalling on the angiogenic activity of SCDC2 cells, the MEK inhibitor U0126 $(20 \mu \mathrm{M})$ and the PI3K inhibitor LY294002 $(20 \mu \mathrm{M})$ were added to three-dimensional cultures of SCDC2 cells in a type I collagen scaffold. U0126 did not affect the formation of vessels originating from the spheroidal aggregates (fig. 9c), but Western blotting analysis revealed that U0126 completely suppressed FGF-induced phosphorylation of p44/42 MAPK (data not shown). In contrast, LY294002 completely suppressed the formation of vessels originating from the spheroidal aggregates (fig. 9d).

We next evaluated the effect of the PI3K inhibitor on the growth and differentiation of SCDC2 cells. As shown in figure 9e, LY294002 inhibited the proliferation of SCDC2 cells by approximately $30 \% 30 \mathrm{~h}$ after administration of the PI3K inhibitor to SCDC2 cell cultures. The TUNEL assay, however, revealed that LY294002 did not exert a pro-apoptotic effect on SCDC2 cells (data not shown). Intriguingly, LY294002 significantly suppressed the expression of the EC-definitive markers FLK-1 and Tie-2 mRNA (fig. 9f).

\section{Discussion}

Here we evaluated the expression of MSC markers in PDL fibroblasts. RT-PCR analysis revealed that all 4 SCDCs originating from cultured primary PDL fibroblasts consistently expressed mRNA for MSC markers, that is, CD44, VCAM1, SM $\alpha$-actin, and ALP (fig. 2a). Expression of MSC markers was also observed in cultured primary PDL fibroblasts (fig. 2a), suggesting that the MSC markers were consistently expressed from the time of PDL fibroblast primary culture establishment in FGF1 and heparin supplemented media. Tsutsumi et al. [31] previously demonstrated that FGF is a potent mitogen for MSCs, and that incubation with FGF maintained the multilineage differentiation potential of MSCs throughout many mitotic divisions. It seems reasonable to hypothesise that FGF stimulation might maintain consistent expression of MSC markers in PDL fibroblasts throughout many mitotic divisions. Recent reports have also shown that PDL fibroblasts express scleraxis, a specific marker of tendons and ligaments [7,29]. All 4 SCDCs also expressed scleraxis mRNA, although slight differences in expression levels were observed (fig. 2b). These observations indicate that these cells possess characteris- tics of both undifferentiated mesenchymal cells and PDL fibroblasts.

We previously demonstrated the ability of a swine PDL fibroblast cell line, TesPDL3, to simultaneously express both EC-specific marker genes and PDL-related genes [8]. Here we evaluated the status of vascular phenotype expression in SCDCs by RT-PCR analysis using specific primers to detect the mRNAs of EC and SMC marker genes. In the present study, SCDC1-4 cells expressed EC and SMC markers in addition to MSC and ligament fibroblast markers (fig. 2, 3, 7). Therefore, it seems reasonable to conclude that SCDCs may be undifferentiated mesenchymal cells that do not express a specific cell type but possess a mixture of different cell features.

Blood vessels are composed of two cell types. ECs line the interior of the vessels, forming channels that allow blood flow, while SMCs cover the outside, protecting the fragile channels from rupture and controlling blood flow. Yamashita et al. demonstrated that both ECs and SMCs develop from the same precursor, that is, Flk-1-expressing cells derived from ESCs [32]. They showed that some cells simultaneously exhibit both EC and SMC markers during terminal differentiation of the common precursor into ECs or SMCs, suggesting that such EC and SMC marker-positive cells might represent incompletely differentiated common precursors of ECs and SMCs. In addition, we previously reported that a small population of human umbilical vein endothelium-derived cells demonstrated simultaneous expression of both EC and SMC markers [33]. In the present study, SCDC1-4 cells simultaneously expressed EC and SMC markers (fig. 3). Therefore, PDL fibroblasts seem to have the same characteristics as the common precursor of ECs and SMCs. Moreover, we found that the originally established primary PDL fibroblast cultures contained a common precursor of ECs and SMCs such that they expressed both vWF and h1-calponin, as revealed by immunocytochemical analyses. This suggests that such a common precursor actually resides in PDL tissue dissected from molars (data not shown).

Here we evaluated the ability of rat PDL fibroblasts to construct a blood vessel-like structure with a mature lumen in a type I collagen gel scaffold. Intriguingly, SCDC2 cells, which demonstrated abundant expression of the EC-specific markers Flk-1 and Tie-2 (fig. 3a), displayed vigorous formation of many thick tube-like structures from the surface of the cell cluster (fig. 4b). However, SCDC1 cells, which expressed only a small amount of Flk-1 and Tie-2, but high levels of expressed osterix, formed only a few thin, fibre-like structures (fig. 4c). We 
previously reported that bone morphogenetic protein, which induces osteoblastic differentiation of the swine PDL fibroblasts, TesPDL3, inhibited their formation of tube-like structure, suggesting that stimulation of osteoblastic differentiation might attenuate EC differentiation of PDL fibroblasts [8]. These results support the idea that SCDC1 cells positive for the definitive osteoblastic marker osterix possess little ability to construct vessel-like structures.

As shown in figure 5, 6 and 8, we demonstrated that PDL fibroblasts can construct definitive EC-specific marker Tie-2-positive blood vessel structures with a mature lumen in a type I collagen gel. Intriguingly, as shown in figure $6 \mathrm{~d}-\mathrm{m}$, we observed a single continuous lumen throughout the 50- $\mu \mathrm{m}$-long vessel-like structure, which was visible in fluorescent-scanned images of sequential sections of the cell culture in a type I collagen scaffold embedded in celloidin. The ability of SCDC2 cells to construct a mature lumen in the vessel-like structure was confirmed by observation of sequential sections of formalin-fixed, paraffin-embedded cultured cells under a bright-field microscope (fig. $5 \mathrm{e}-\mathrm{j}$ ). In addition, as shown in figure $8 \mathrm{c}$ and $\mathrm{d}$, Tie-2 expression was clearly detected in the vessel-like structure or around the edge of spheroidal aggregates. However, no Tie-2 expression was detected at the centre of spheroidal aggregates. These results suggest that the cells around the surface of the spheroidal aggregates differentiated into mature ECs and possessed angiogenic activity.

Shankar et al. [19] reported that PI3K/Akt and MEK/ ERK activation seem to positively regulate angiogenesis by human umbilical vascular endotherial cells in vitro. As shown in figure 9a-d, the MEK inhibitor U0126 did not affect the ability of SCDC2 cells to construct a vessellike structure. In contrast, the PI3K inhibitor LY294002 totally suppressed this ability. These results indicate that the ability of SCDC2 to construct a blood vessel-like structure is dependent on PI3K, but not on MEK/ERK activation. In addition, LY294002 moderately inhibited the proliferation of SCDC2 cells and also suppressed the mRNA expression of the EC-definitive markers FLK-1 and Tie-2 in these cells (fig. 9e, f). Therefore, it seems reasonable to postulate that PI3K-dependent intracellular signalling plays an important role not only in the proliferation and differentiation but also in the angiogenic activity of PDL fibroblasts.

To make it clear that the expressions of the mixture of different cell features in SCDC2 was not due to the contamination of MSC, EC and SMC into the ligament fibroblast culture, we examined the expression levels of vari- ous differentiation markers in the SCDCs originating from SCDC2 cells. The SCDCs originating from SCDC2 cells expressed MSC, ligament fibroblast, EC and SMC markers, as did the original SCDC2 cells (data not shown). Moreover, the SCDCs originating from SCDC2 cells formed a tube-like structure in a three-dimensional type I collagen scaffold similar to that formed by original SCDC2 cells (data not shown). These results prove that ligament fibroblasts can express a mixture of different cell features.

Blood supply is indispensable for the regeneration of damaged or lost PDL tissue [34]. An understanding of how PDL tissue recruits the precursors of vascular cells and how the precursors differentiate into vascular cells is necessary for the establishment of a practical strategy of regenerative therapy for damaged or lost PDL. This is the first report to show that PDL fibroblasts have the vascular cell-like potential to construct blood vessel-like structures that express vascular cell-specific markers and have a lumen, and that this phenomenon is dependent on PI3K activation. Here we propose a novel idea that the fibroblastic lineage in the ligament tissue could be a candidate precursor for construction of a vascular system around damaged ligament tissue to facilitate its regeneration.

\section{Acknowledgments}

We are grateful to Yoshiyuki Honma for technical support in the morphological study. Skilled technical assistance was kindly provided by Shiro Mizogami. We also thank all members of the Support Section for Education and Research, Graduate School of Dental Medicine, Hokkaido University for useful discussions. This work was supported by a Grant-in-Aid for Scientific Research $(18592026,20592169)$ from the Japan Society for the Promotion of Science.

References

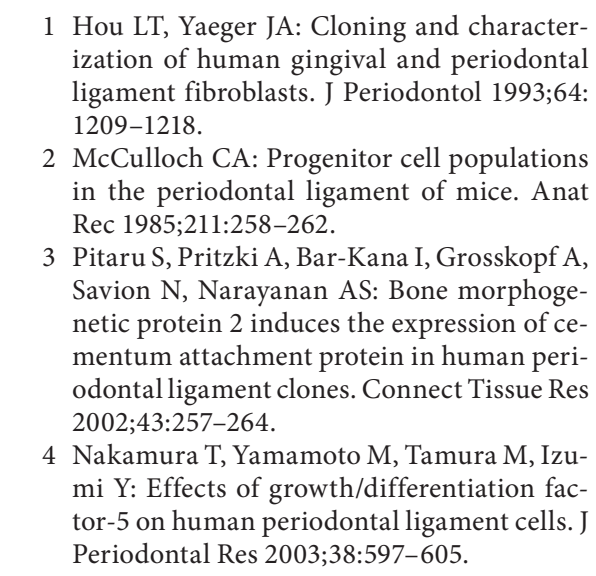

Okubo/Ishisaki/Iizuka/Tamura/ Kitagawa 
5 Trubiani O, Isgro A, Zini N, Antonucci I, Aiuti F, Di Primio R, Nanci A, Caputi S, Paganelli R: Functional interleukin-7/interleukin-7R $\alpha$, and SDF-1 $\alpha / C X C R 4$ are expressed by human periodontal ligament derived mesenchymal stem cells. J Cell Physiol 2008;214:706-713.

-6 Shi S, Bartold PM, Miura M, Seo BM, Robey PG, Gronthos S: The efficacy of mesenchymal stem cells to regenerate and repair dental structures. Orthod Craniofac Res 2005;8: 191-199.

7 Seo BM, Miura M, Gronthos S, Bartold PM, Batouli S, Brahim J, Young M, Robey PG, Wang CY, Shi S: Investigation of multipotent postnatal stem cells from human periodontal ligament. Lancet 2004;364:149-155.

8 Shirai K, Ishisaki A, Kaku T, Tamura M, Furuichi Y: Multipotency of clonal cells derived from swine periodontal ligament and differential regulation by fibroblast growth factor and bone morphogenetic protein. J Periodontal Res, in press.

$\checkmark 9$ Narmoneva DA, Oni O, Sieminski AL, Zhang S, Gertler JP, Kamm RD, Lee RT: Selfassembling short oligopeptides and the promotion of angiogenesis. Biomaterials 2005; 26:4837-4846.

10 Davis ME, Motion JP, Narmoneva DA, Takahashi T, Hakuno D, Kamm RD, Zhang S, Lee RT: Injectable self-assembling peptide nanofibres create intramyocardial microenvironments for endothelial cells. Circulation 2005; 111:442-450.

-11 Penta K, Varner JA, Liaw L, Hidai C, Shatzman R, Quertermous T: Del1 induces integrin signaling and angiogenesis by ligation of $\alpha$ V $\beta 3$. J Biol Chem 1999;274:1110111109.

-12 Urbich C, Dernbach E, Reissner A, Vasa M, Zeiher AM, Dimmelar S: Shear stress-induced endothelial cell migration involves integrin signaling via the fibronectin receptor subunits $\alpha_{5}$ and $\beta_{1}$. Arterioscler Thromb Vasc Biol 2002;22:69-75.

-13 Zhang Y, Hu X, Tian R, WeiW, Hu W, Chen $\mathrm{X}$, Han W, Chen H, Gong Y: Angiopoietinrelated growth factor (AGF) supports adhesion, spreading, and migration of keratinocytes, fibroblasts, and endothelial cells through interaction with RGD-binding integrins. Biochem Biophys Res Commun 2006; 347:100-108.
14 Ingham KC, Brew SA, Migliorini M: Type I collagen contains at least 14 cryptic fibronectin binding sites of similar affinity. Arch Biochem Biophys 2002, 407:217-223.

15 Ibi M, Ishisaki A, Yamamoto M, Wada S, Kozakai T, Nakashima A, Iida J, Takao S, Izumi Y, Yokoyama A, Tamura M: Establishment of cell lines that exhibit pluripotency from miniature swine periodontal ligaments. Arch Oral Biol 2007;52:1002-1008.

16 Li H, Zhou J, Miki J, Furusato B, Gu Y, Srivastava S, McLeod DG, Vogel JC, Rhim JS: Telomerase-immortalised non-malignant human prostate epithelial cells retain the properties of multipotent stem cells. Exp Cell Res 2008;314:92-102.

$\checkmark 17$ Murphy DA, Makonnen S, Lassoued W, Feldman MD, Carter C, Lee WM: Inhibition of tumor endothelial ERK activation, angiogenesis, and tumor growth by sorafenib (BAY43-9006). Am J Pathol 2006;169:18751885.

18 Yang YH, Wang Y, Lam KS, Cheng KK, Zhang J, Zhu W, Wu D, Xu A: Suppression of the Raf/MEK/ERK signaling cascade and inhibition of angiogenesis by the carbpxyl terminus of angiopoietin-like protein 4 . Arterioscler Thromb Vasc Biol 2008;28:835840.

19 Shankar S, Chen Q, Srivastava RK: Inhibition of PI3K/AKT and MEK/ERK pathways act synergistically to enhance antiangiogenic effects of EGCG through activation of FOXO transcription factor. J Mol Signal 2008;3:7.

20 Harmer NJ: Insights into the role of heparan sulphate in fibroblast growth factor signaling. Biochem Soc Trans 2006;34:442-445.

-21 Alajati A, Laib AM, Weber H, Boos AM, Bartol A, Kristian I, Korff T, Zentgraf H, Obodozie C, Graeser R, Chiristian S, Finkenzeller G, Stark GB, Héroult M, Augustin HG: Spheroid-based engineering of a human vasculature in mice. Nat Methods 2008;5:439445.

22 Ishiyama M, Miyazono Y, Sakamoto K, Ohkuma Y, Ueno K: A highly water-soluble disulfonated tetrazolium salt as a chromogenic indicator for NADH as well as cell viability. Taranta 1997;44:1299-1305.

-23 Gabrieli Y, Sherman Y, Ben-Sasson SA: Identification of programmed cell death in situ via specific labeling of nuclear DNA fragmentation. J Cell Biol 1992;119:493-501.
24 Giannopoulou C, Cimasoni G: Functional characteristics of gingival and periodontal ligament fibroblasts. J Det Res 1996;75:895902.

25 Ivanovski S, Gronthos S, Shi S, Bartold PM: Stem cells in the periodontal ligament. Oral Dis 2006;12:358-363.

-26 Gronthos S, Mankani M, Brahim J, Robey PG, and Shi S: Postnatal human dental pulp stem cells (DPSCs) in vitro and in vivo. PNAS 2000;97:13625-13630.

27 Baksh D, Yao R, Tuan RS: Comparison of proliferative and multilineage differentiation potential of human mesenchymal stem cells derived from umbilical cord and bone marrow. Stem Cells 2008;25:1384-1392.

28 Sorrentino A, Ferracin M, Castelli G, Biffoni M, Tomaselli G, Baiocchi M, Fatica A, Negrini $\mathrm{M}$, Peschle C, Valtieri M: Isolation and characterization of CD146+ multipotent mesenchymal stromal cells. Exp Hematol 2008;30:1035-1046.

29 Fujii S, Maeda H, Wada N, Tomikiyo A, Saito $\mathrm{M}$, Akamine A: Investigating a clonal human periodontal ligament progenitor/stem cell line in vitro and in vivo. J Cell Physiol 2008;215:743-749.

30 Bogdanovic E, Nguyen VP, Dumont DJ: Activation of Tie 2 by angiopoietin-1 and angiopoietin- 2 results in their release and receptor internalization. J. Cell Sci 2006;119:35513560 .

-31 Tsutsumi S, Shimazu A, Miyazaki K, Pan H, Koike C, Yoshida E, Takagishi K, Kato Y: Retention of multilineage differentiation potential of mesenchymal cells during proliferation in response to FGF. Biochem Biophys Res Commun 2001;288:413-419.

32 Yamashita J, Itoh H, Hirashima M, Ogawa M, Nishikawa S, Yugiri T, Naito M, Nakao K, Nishikawa S: Flk1-positive cells derived from embryonic stem cells serve as vascular progenitors. Nature 2000;408:92-96.

33 Ishisaki A, Hayashi H, Li AJ, Imamura T: Human umbilical vein endothelium-derived cells retain potential to differentiate into smooth muscle-like cells. J Biol Chem 2003; 278:1303-1309.

34 Bartold PM, Shi S, Gronthos S: Stem cells and periodontal regeneration. Periodontol 2000 2006;40:164-172. 